Research article

\title{
Attributional life cycle assessment of biofuels for shipping: Addressing alternative geographical locations and cultivation systems
}

\author{
Uchenna Kesieme $^{\mathrm{a}, \mathrm{b}, *}$, Kayvan Pazouki ${ }^{\mathrm{b}}$, Alan Murphy ${ }^{\mathrm{b}}$, Andreas Chrysanthou ${ }^{\mathrm{a}}$ \\ ${ }^{a}$ School of Engineering and Technology, University of Hertfordshire, Hatfield, AL10 9AB, UK \\ ${ }^{\mathrm{b}}$ School of Engineering and Marine Science, Newcastle University, Queen Victoria Road, Newcastle upon Tyne, NE1 7RU, UK
}

\section{A R T I C L E I N F O}

\section{Keywords:}

Life cycle assessment

SVO

Biodiesel

Emission and shipping

\begin{abstract}
A B S T R A C T
The purpose of this study is to evaluate a life cycle assessment of straight vegetable oil (SVO) and biodiesel addressing alternative upstream pathways. The pathways are SVO and biodiesel produced in the United Kingdom (UK) using European rapeseed and also, SVO and biodiesel produced in the UK using soybean grain and soybean oil imported from Argentina. Four environmental impact categories have been assessed using the SimaPro (ReCiPe life-cycle impact assessment) method: this includes global warming potential (GWP); acidification; eutrophication and particulate matter. Rapeseed based biofuel had the lowest emission impact in terms of GHG emissions. Significant greenhouse gas (GHG) emissions can result from land use change due to the expansion and cultivation of soybean in Argentina. When land use change is not considered, the soy based biofuel system has the lowest GHG impact with more than 70\% GHG emission reduction. The GHG emission at cultivation stage far outweighs the impacts of the other life-cycle stages irrespective of the feedstock used for the biofuel production systems. The use of fertilizers and associated soil emissions are the main contributors. The environmental impacts of biofuel can be reduced by avoiding land use change, improving soil management practices and yield, and also optimizing transportation routes. Effective implementation of options for biofuels production were explored to improve sustainability in shipping.
\end{abstract}

\section{Introduction}

Shipping plays a key role in global trade, carrying more than $80 \%$ of the world's trade by volume (Taljegard et al., 2014). However, the shipping sector consumes a substantial amount of fossil fuel, mainly heavy fuel oil (HFO), and contributes greatly to atmospheric pollution by releasing $\mathrm{SO}_{\mathrm{X}}, \mathrm{NO}_{\mathrm{X}}, \mathrm{PM}$ and greenhouse gas (GHG) emissions. Approximately $14-31 \%, 4-9 \%$, and $3-6 \%$ of the global emissions of NOx, $\mathrm{SO}_{\mathrm{X}}$, and $\mathrm{CO}_{2}$, respectively, are from marine vessels (Gilbert et al., 2018; Taljegard et al., 2014). A report commissioned by the International Maritime Organization (IMO) assessed shipping to be responsible for approximately $1.1 \mathrm{Gt} \mathrm{CO}_{2}$ in 2007 , of which international shipping accounted for $0.9 \mathrm{Gt} \mathrm{CO}_{2}$ (Anderson and Bows, 2011; Rehmatulla and Smith, 2015). The share has also been projected to increase: in the past two decades, the shipping sector has grown by $4.1 \%, 1.2$ percentage points faster than the global gross domestic product (GDP) (Rehmatulla and Smith, 2015). The $\mathrm{CO}_{2}$ emissions from shipping are projected in the range of $1.1-3.7 \mathrm{Gt} \mathrm{CO}_{2} / \mathrm{yr}$ in 2050 , an up to $270 \%$ increase compared to 2007 in a business-as-usual scenario (Rehmatulla and Smith, 2015).

Marine transportation is facing harder requirements on fuel quality and exhaust emissions as stricter regulations are enforced in different regions of the world (Brynolf, 2014; Brynolf et al., 2014). For example, the sulphur content of the fuel of ships needs to be $0.1 \%$ since 2015 and $0.5 \%$ by 2020 while operating in Emission Control Areas (ECA) and in international waters, respectively (Florentinus et al., 2012). In addition, MARPOL Annex VI includes regulation on NOx emissions and there is also a need to address NOx and particulate matter (PM) emissions at a localised level (Gilbert et al., 2018). The regulatory changes affecting HFO has driven an increased interest in low-sulphur fuels. A notable example is the potential to switch from established marine fuels to more novel or emergent alternatives such as bio-derived fuels (Bengtsson et al., 2012; Gilbert et al., 2018). A number of alternative fuels have been proposed as viable and potential alternatives: these are Straight Vegetable Oil (SVO) and biodiesel in the short and medium term and in the longer term, pyrolysis oil and Fischer-Tropsch (FT) biodiesel (Gilbert et al., 2018). However, the sustainability of first-generation biofuels is debated due to competition in using land with food production, limited production potential and questionable environmental performance (Brynolf et al., 2014; Florentinus et al., 2012; Gilbert et al., 2018). The risk of indirect land use change has led some to

\footnotetext{
* Corresponding author. School of Engineering and Technology, University of Hertfordshire, Hatfield, AL10 9AB, UK.

E-mail address: u.kesieme@herts.ac.uk (U. Kesieme).
} 
question the carbon savings that are achieved through some crop-based biofuels, and to turn attention to feedstocks such as wastes and residues (Bengtsson et al., 2012; Gilbert et al., 2018). Using these feedstocks in advanced production processes could, in the longer-term, allow for the production of liquid bio-derived fuels such as pyrolysis oil and FT diesel (Gilbert et al., 2018). However, it is argued that second-generation biofuels can avoid many of the concerns facing first-generation biofuels, and still face economic and technical challenges (Brynolf et al., 2014; Florentinus et al., 2012; Gilbert et al., 2018). More advanced bio-derived fuels are still immature with little prospective of significant market penetration before 2020 (Gilbert et al., 2018; Milazzo et al., 2013).

Focusing on bio-derived fuels in particular, in the short to medium term provides some potentially important future sources of biomass feedstocks, conversion pathways and fuels that have the potential to expand production and feed into the shipping sector as a lower carbon, alternative fuel. In terms of the emissions released during ship operation, many of these fuels present (on first evaluation) attractive alternatives as they represent a much lower direct emission burden (Brynolf, 2014; Brynolf et al., 2014; Florentinus et al., 2012; Gilbert et al., 2018; Milazzo et al., 2013). However, production of biofuels requires fossil inputs and may incur the release of emissions at a different stage of the life-cycle. For example, emissions could be generated during production and refining or transportation, and/or may be derived from biomass feedstocks, which have life-cycle impacts associated with growth, landuse change and agricultural inputs (Bengtsson et al., 2011, 2012; Gilbert et al., 2018; Milazzo et al., 2013). Considering the environmental life-cycle impacts of these fuels, it is an essential step to ensure that any alternative fuel is able to deliver meaningful emission savings for the sector as a whole (Castanheira et al., 2015; Dalgaard et al., 2008; Malca et al., 2014). As a result, an attributional life cycle assessment approach (ALCA) is used to assess the environmental impacts at a fuelcycle level.

This study addresses the upstream pathways towards environmentally effective biofuels for shipping. The pathways considered are SVO and biodiesel produced in the UK using European rapeseed and also, SVO and biodiesel produced in the UK using Argentinean soybean grain and soybean oil. The impact categories assessed include global warming potentials, acidification, particulate matter, and eutrophication. The impact categories were selected to reflect the current regulatory changes and requirements of a shipping fuel. In order to achieve the above aim, this study addresses the following research questions:

1. What are the system level well to Tank $\mathrm{CO}_{2} / \mathrm{CO}_{2} \mathrm{eq}$ inventory emissions associated with the alternative fuels and fuel scenarios?

2. What are the system level $\mathrm{SO}_{\mathrm{X}} / \mathrm{NO}_{\mathrm{X}} / \mathrm{PM}$ inventory emissions associated with the alternative fuels and fuel scenarios?

\section{Scope and boundary}

\subsection{Existing LCA literature and data}

This investigation draws on previous life-cycle studies addressing alternative fuels in the transportation sector. A number of studies have assessed the LCA performance of the currently used fossil marine fuels (Corbett and Winebrake, 2008; Petzold et al., 2011; Proskilly et al., 2008; Winebrake et al., 2007). Winebrake et al. (2007) included biofuels, but only soybean based biodiesel blend. In these studies lifecycle inventory results were presented in terms of emissions per normalised unit (e.g. per reference trip) and the actual environmental impact was not quantified. More recent studies have adopted a consequential LCA approach, to address the sectoral impact of fuel switching on emissions, within a defined annual provision of shipping services (Bengtsson et al., 2012; Brynolf, 2014; Brynolf et al 2014). These studies widen the choice of available fuels, including the uptake of bio-derived fuels along liquid and gaseous fuel conversion routes, including bio-methanol and liquefied bio-methane. The impact assessment is presented in terms of acidification potential and global warming potential (GWP), and includes life-cycle stages from feedstock production to vessel operation. Whilst this study is region specific it seeks to represent a sectoral transition from diesel to LNG and methanol. Here, significant greenhouse gas reductions are only achievable through arguably a more dramatic fuel switch to liquid bio-gas and bio-methanol.

The shipping industry has limited experience of biofuels so far, and most biofuel LCA studies have been directed toward land based transportation (Esteban et al., 2011; Fazio and Monti, 2011; Lechón et al., 2009; Malça and Freire, 2010, 2011; Thamsiriroj and Murphy, 2011; Reijnders and Huijbregts, 2008; Koponen et al., 2013). However, there are some aspects in road based transport that differs to that of shipping. Firstly, the basis for comparison differs, as the fuels used at present in shipping (mainly heavy fuel oils) are different from those used for road vehicles (gasoline and diesel). The infrastructure need and the storage requirements also differ as do the engines. It is therefore possible that fuels not well adjusted for road transport may be advantageous as marine fuels and vice versa. Given the prominent role of fuel switching in many emission scenarios across different sectors, application of lifecycle analysis is particularly important, especially for emerging fuels such as bioderived fuels.

Important environmental concerns have emerged regarding carbon stock changes due to the land use changes (LUC), cultivation and transportation of feedstock for biofuels (Malça and Freire, 2010, 2011). Alternative land use change scenarios, transportation and cultivation systems, can result in significant greenhouse gas (GHG) emissions and the results can vary widely due to several factors, namely: i) the uncertainty of soil emissions, in particular nitrous oxide, and carbon dioxide $\left(\mathrm{CO}_{2}\right)$ emissions due to LUC; ii) the diversity of soil management practices, material inputs, locations and yields and iii) the types of transport in question.

Some LCA studies on land based transportation accounted for the carbon stock changes due to land-use change (LUC), as well as field emissions from cultivation, showing that they are highly site-specific (Esteban et al., 2011; Fazio and Monti, 2011; Lechón et al., 2009; Malça and Freire, 2010). However, the variability in cultivation conditions as well as the influence of different climate vegetation and soil regions on the results have not been comprehensively addressed. There is no known LCA study of biofuel for shipping addressing cultivation and geographical variability.

This study examines the upstream pathways towards environmentally effective biofuels for shipping. The pathways are as follows: rapeseed based SVO and biodiesel produced in the UK using European rapeseed as feedstock, and also, SVO and biodiesel produced in the UK using soybean grain and soybean oil imported from Argentina. The life cycle stages examined for both systems include the agricultural stage, extraction, refining, esterification, and bunkering and pumping.

With regards to data it should be noted that no primary data was developed in terms of inventory data. The ALCA use existing studies and secondary data to generate the emissions inventory. At each upstream life-cycle stage, secondary data was used whenever possible to best represent the systems modelled - otherwise, existing professional and transparent life-cycle data, in particular Eco-invent version 3.5, was used. For standard and second order processes, such as material or machinery production, Eco-invent 3.5 was also used and selected to represent best available practices in the given country.

\subsection{System definition}

\subsubsection{Flow diagram of the main stages of biofuel production}

Figs. 1 and 2, describe the upstream pathways for the production of soybean and rapeseed based SVO and biodiesel. The pathways examined are outlined as follows:

For the Straight Vegetable Oil (SVO) 


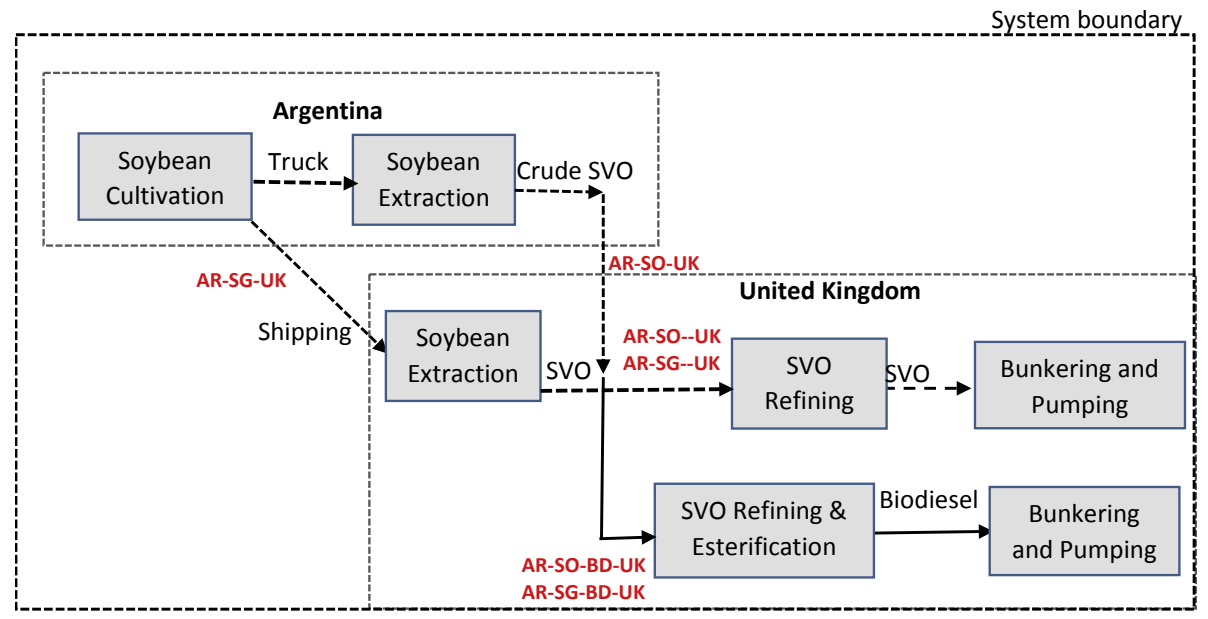

Fig. 1. Soybean based SVO and biodiesel production chain: Alternative pathways.

- SVO produced in UK via extraction using soybean grain (SG) imported from Argentina (AR-SG-UK)

- SVO produced in UK via refining using crude straight vegetable oil (SO) imported from Argentina (AR-SO-UK)

- SVO produced in UK via extraction using rapeseed grain (RS) produced in the UK (UK-RS-UK)

For the Biodiesel production

- Biodiesel produced in the UK via esterification process using soybean grain imported from Argentina (AR- SG-BD-UK)

- Biodiesel produced in the UK via esterification using soybean oil imported from Argentina (AR-SO-BD-UK)

- Biodiesel produced in UK via an esterification process using rapeseed grain established in the UK (UK-RS-BD-UK)

\subsubsection{Feedstock selection and producer region}

The feedstocks selected for biodiesel (and SVO) are Argentine soybean and EU rapeseed grain. The rationale for the selection of the study region is as follows: The European Union holds the leading position at worldwide level in terms of biofuel production and consumption (Malca et al., 2014). The most used raw material is rapeseed, accounting for nearly $80 \%$ of the total European biodiesel feedstock (Malca et al., 2014; Castanheira et al., 2015). Furthermore, the EU imports a substantial amount of soybean grain and also produces rapeseed grain indigenously for intra-EU use (Malca et al., 2014). Brazil and Argentina are the EU's leading suppliers of soybean (40-70\%) and soybean meal (50-55\%) respectively (Dalgaard et al., 2008). The Republic of Argentina is the first exporter of soybean oil and meal and also among the largest soybean producer in the world (Malca et al., 2014; Castanheira et al., 2015). Soybean-based biofuel production in Argentina is expected to significantly increase in the near future, mostly for exportation (Dalgaard et al., 2008; Gilbert et al., 2018).

\subsection{Allocation and multifunctionality}

The SVO and biodiesel systems are multifunctional with SVO and meal being produced in the oil extraction stage as well as glycerine and biodiesel in the transesterification stage (Castanheira et al., 2015; Dalgaard et al., 2008; Malca et al., 2014; Nemecek et al., 2012, 2014). Multifunctional processes are an issue in LCA because not all the functional flows are part of the same product system. The key issue now is how to allocate the environmental impacts of multifunctional processes to the different product systems. Different approaches were adopted in the literature to deal with the co-products of biofuels: allocation based on mass, energy, and economic value as well as system boundary expansion. In this paper, economic and mass allocation were considered and adopted for biofuel systems and based on the literature (Malca et al., 2014; Castanheira et al., 2015; Dalgaard et al., 2008). A sensitivity analysis to alternative allocation procedures was performed to evaluate the influence on the results, as suggested by ISO14044 standards (Malca et al., 2014). Mass allocation was calculated by directly distributing the environmental burdens proportionally to the mass of each product (Milazzo et al., 2013; Malca et al., 2014). Price allocation factors were obtained based on the world average annual prices of oil and meal in the 2009 to 2013 period. (Milazzo et al., 2013; Malca et al., 2014). The average annual price of biodiesel (2009-2013 period) was based on the price paid to biodiesel producers, according to EU regulations (Malca et al., 2014; Castanheira et al., 2015). The price of glycerine was adopted from literature (Dalgaard et al., 2008). The allocation factors and co-product data for soybean and rapeseed based SVO and biodiesel are shown Tables 1 and 2

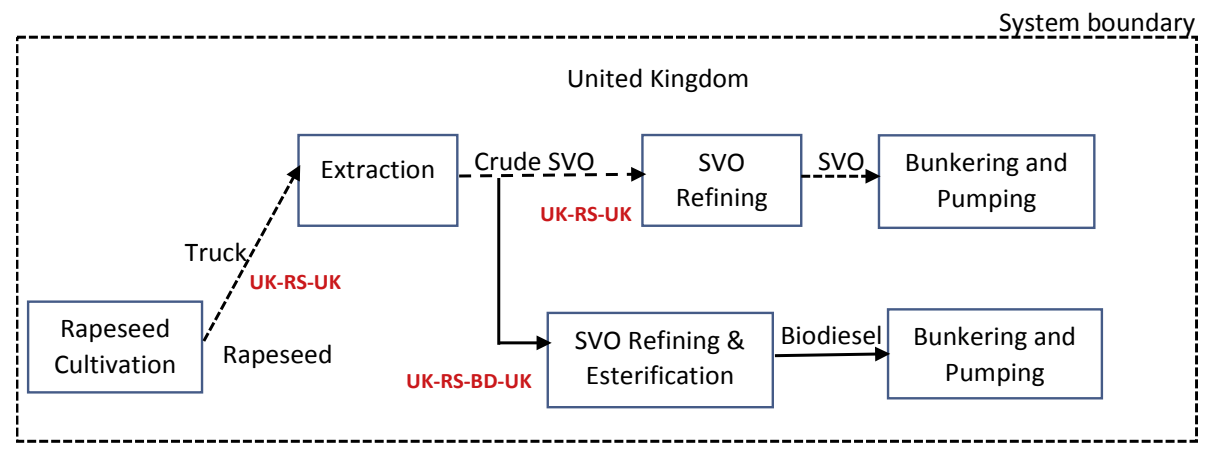

Fig. 2. Rapeseed based SVO and biodiesel production chain: Alternative pathways. 
Table 1

Allocation factors and co-product data for soy based SVO and biodiesel.

\begin{tabular}{|c|c|c|c|c|c|c|}
\hline \multirow[t]{2}{*}{ Steps allocated } & \multirow[t]{2}{*}{ Products } & \multirow[t]{2}{*}{ Mass allocation [\%] } & \multicolumn{4}{|c|}{ Economic allocation Market price (\$US per ton) } \\
\hline & & & Max Price & Min-Price & Average & Allocation [\%] \\
\hline \multirow[t]{2}{*}{ Extraction } & Crude SVO & 20 & 1216 & 1024 & 1021 & 65 \\
\hline & Cake & 80 & 379 & 476 & 404 & 35 \\
\hline \multirow{2}{*}{ Refining } & SVO & 99 & - & & - & 99 \\
\hline & Acid Oil & 1 & - & & - & 1 \\
\hline \multirow[t]{3}{*}{ Esterification } & Biodiesel & 89 & - & & 1078 & 98.4 \\
\hline & Glycerol & 10 & - & & 100 & 1.1 \\
\hline & Acid oil & 1 & - & & - & 0.5 \\
\hline
\end{tabular}

\section{Attributional life cycle assessment (ALCA)}

ALCA is based on system analysis and handles the process as a chain of subsystems that exchange inputs and outputs (Brynolf, 2014; Brynolf, et al., 2014). According to ISO14044 standards, an LCA has four interrelated phases: the goal and scope definition (including the definition of a functional unit and system boundaries), the Life-Cycle Inventory (LCI), the Life-Cycle Impact Assessment (LCIA) and interpretation (Malca et al., 2014). A process based on a well-to-tank ALCA method was applied as the technique to assess the environmental impacts of SVO and biodiesel production systems. ALCA includes all steps from resource cultivation to final distribution of the fuel as shown in Figs. 1 and 2. The LCIA was carried out based on the inventory analysis data generated for the unit processes. The impacts were assessed using the ReCiPe life-cycle impact assessment (LCIA) method. The software package SimaPro 8.0.5 (Pré Consultants, The Netherlands) was chosen because it is a widely used LCA tool, both by professionals and researchers (Malca et al., 2014; Castanheira et al., 2015). The functional unit selected is tonne of fuel delivered (to the vessel). This accounts for the upstream life-cycle emissions associated with delivering the fuel to the vessel. For example, the $\mathrm{CO}_{2}$ emissions associated with the manufacturing of a fuel is provided as $\mathrm{kg} \mathrm{CO}_{2} /$ tonne of fuel delivered.

\subsection{Impacts categories and characterisation factor}

The types of the impacts that were studied in the Life Cycle Impact Assessment (LCIA) include $\mathrm{CO}_{2}$ equivalent $\left(\mathrm{CO}_{2}, \mathrm{CH}_{4}\right.$ and $\left.\mathrm{N}_{2} \mathrm{O}\right)$ to assess Global Warming Potential; SOx and NOx to assess Acidification and Eutrophication Potential and; PM emissions. The characterisation factors used for impact categorization are shown in Table 3. The characterisation factors are taken from a database compiled by the Institute of Environmental Sciences (CML) at University of Leiden (Brynolf, 2014).

\subsection{Life cycle inventory (LCI)}

LCI background data include inputs and outputs in processes for the production of accessory materials and process energies, as well as the
Table 3

Characterisation factors for the impact categories.

\begin{tabular}{llll}
\hline Compounds & $\begin{array}{l}\text { Global warming } \\
\text { potentials }[\mathrm{Kg} \\
\mathrm{CO}_{2} \text { eq] }\end{array}$ & $\begin{array}{l}\text { Acidification }[\mathrm{Kg} \\
\mathrm{SO}_{2} \text { eq] }\end{array}$ & $\begin{array}{l}\text { Eutrophication }[\mathrm{P} \\
\mathrm{kg} \mathrm{eq}]\end{array}$ \\
\hline $\mathrm{CO}_{2}$ & 1 & - & - \\
Methane & 25 & - & - \\
Nitrous oxide & 298 & - & - \\
Nitrogen & - & 1.07 & 0.2 \\
$\quad$ monoxide & & 0.7 & 0.13 \\
Nitrogen dioxide & - & 0.7 & 0.13 \\
Nitrogen oxides & - & 1.0 & - \\
Sulphur dioxide & - & - & - \\
Carbon monoxide & - & - & 0.35 \\
Ammonia & - & & \\
\hline
\end{tabular}

direct emissions, such as, the production of steam, electricity, fertilizers, diesel, pesticides, and chemicals (Rocha et al., 2014). The inventory data collated includes $\mathrm{CO}_{2}$ uptake by the plant, land use change, cultivation, oil extraction and refining, transesterification and bunkering.

\subsubsection{Land use change (LUC) and carbon stock changes}

The amount of land transformed is the area required to produce 1 functional unit of a product. Land use change has impacts on soil properties (e.g. carbon content, compaction, nutrients leaching, $\mathrm{N}_{2} \mathrm{O}$ emissions among others), on biodiversity, on biotic production and on other environmental aspects such as landscape, and evapotranspiration. An important aspect in the GHG assessment of biofuels is the change in agricultural practices, which may induce soil carbon variations (release or sequestration) depending on the prior and actual management practices adopted (Hennecke et al., 2013; Tonini and Astrup, 2012). To address this issue, this study assesses the most representative cultivation system for rapeseed and soybean and evaluates the implications of changing soil management activities. European rapeseed is assumed to be cultivated in existing cropland (Castanheira et al., 2015; Malca et al., 2014), while Argentine soybean is assumed to be mainly associated with an expansion in cultivation areas (Dalgaard et al., 2008). Two scenarios with alternative cultivation practices were examined for both

Table 2

Allocation factors and co-product data for rapeseed based biofuel.

\begin{tabular}{|c|c|c|c|c|c|c|}
\hline \multirow[t]{2}{*}{ Steps allocated } & \multirow[t]{2}{*}{ Products } & \multirow[t]{2}{*}{ Mass allocation [\%] } & \multicolumn{4}{|c|}{ Economic allocation Market price (\$US per ton) } \\
\hline & & & Max Price & Min-Price & Average & Allocation $[\%]$ \\
\hline \multirow[t]{2}{*}{ Extraction } & Crude SvO & 40 & 1306 & 981 & 1143 & 70 \\
\hline & Cake & 60 & 359 & 270 & 314 & 30 \\
\hline \multirow[t]{2}{*}{ Refining } & SVO & 99 & - & & - & 99 \\
\hline & Acid Oil & 1 & - & & - & 1 \\
\hline \multirow[t]{3}{*}{ Esterification } & Biodiesel & 89 & - & & 1078 & 98.4 \\
\hline & Glycerol & 10 & - & & 100 & 1.1 \\
\hline & Acid oil & 1 & - & & - & 0.5 \\
\hline
\end{tabular}


rapeseed and soybean. These include full-tillage; low-tillage; and notillage, based on the level of soil disturbance during cultivation. Low tillage and no-tillage have been considered for the reference land use, whereas full-tillage has been assumed for the actual land use for both rapeseed and soybean cultivation (Milazzo et al., 2013; Malca et al., 2014; Castanheira et al., 2015).

\subsubsection{Rapeseed and soybean cultivation}

The method of cultivation and harvesting of rapeseed grain modelled in this study reflects the usual practice in the UK. The average UK rapeseed yield is $3580 \mathrm{~kg} \mathrm{ha}^{-1}$, where the seed contains $9 \mathrm{wt} \%$ moisture (DEFRA, 2013). The main inputs of soybean production in Argentina were based on the LCI presented by Dalgaard et al. (2008) but adjustments were made for soybean yields (Hilbert et al., 2009; Hilbert, 2010). The yields were calculated for reduced tillage $\left(2677 \mathrm{~kg} \mathrm{ha}^{-1}\right)$ and tillage $\left(2248 \mathrm{~kg} \mathrm{ha}^{-1}\right)$ based on the average yield of $2591 \mathrm{~kg} \mathrm{ha}^{-1}$ (Hennecke et al., 2013). Fertilizer data for soybean was collected following the Argentina fertilizer application rate for soybean cultivation (Hilbert et al., 2009; Hilbert, 2010; Dalgaard et al., 2008). The Nitrogen and $\mathrm{P}_{2} \mathrm{O}_{5}$ fertilizer is assumed to be 5.47 and $20.8 \mathrm{~kg} \mathrm{ha}^{-1}$ respectively (Dalgaard et al., 2008; Hilbert et al., 2009; Hilbert, 2010). No K fertilizer use was applied in soybean production in Argentina (Dalgaard et al., 2008). The fertilizer input for rapeseed cultivation was adapted from DEFRA (2013). Emissions from cultivation and diesel combustion from agricultural operations were calculated based on the literature (Nemecek et al., 2012).

\subsection{3. $\mathrm{CO}_{2}$ up take by plant}

Carbon is taken up in the form of carbon dioxide and fixated in the biomass. The $\mathrm{CO}_{2}$ uptake by the plant is estimated by multiplying the carbon content in the plant dry matter by the stoichiometric factor 44/ 12 (Jungbluth et al., 2007; FAO, 2018). The carbon content of rapeseed is assumed to be $0.73 \mathrm{~kg} / \mathrm{kg}$ rape fresh matter (Nemecek et al., 2014). While the carbon content of soybean is $0.388 \mathrm{~kg} / \mathrm{kg}$ soybean fresh matter (Jungbluth et al., 2007). However, if no composition information (carbon content) was available, $47.5 \%$ was taken as default value for the carbon content of dry mass (FAO, 2018).

\subsubsection{Field emissions}

3.2.4.1. $\mathrm{N}_{2} \mathrm{O}$ emissions. The IPCC et al. (2013) Tier 1 methodology was used to calculate direct and indirect $\mathrm{N}_{2} \mathrm{O}$ emissions. Direct $\mathrm{N}_{2} \mathrm{O}$ emissions occur directly from the soils to which the $\mathrm{N}$ is released from anthropogenic $\mathrm{N}$ inputs or $\mathrm{N}$ mineralization. Indirect $\mathrm{N}_{2} \mathrm{O}$ emissions occur through two pathways (IPCC, 2006) following volatilization of $\mathrm{NH}_{3}$ and $\mathrm{NOx}$ from the soil and the subsequent deposition of these gases and their products $\mathrm{NH}_{4}{ }^{+}$and $\mathrm{NO}_{3}$-to soils and waters and ii) after leaching and runoff of $\mathrm{N}$, mainly as $\mathrm{NO}_{3}$. The amount of $\mathrm{N}$ in crop residues (FCR) was estimated on the basis of the soybean yield and default factors for above-/below-ground residue given by the IPCC (2006).

3.2.4.2. Emissions of $N O_{X}$. During denitrification processes in soils, nitrous oxide (NOx) may also be produced. These emissions were estimated from the emissions of $\mathrm{N}_{2} \mathrm{O}$ and adopted from (Nemecek et al., 2014; Schmidt, 2007) as shown in Equation (1). Since this process is not one of conversion from $\mathrm{N}_{2} \mathrm{O}$ to $\mathrm{NOx}$, but a parallel process, no correction of the $\mathrm{N}_{2} \mathrm{O}$ emissions is required (Nemecek et al., 2014; Schmidt, 2007). This equation includes the direct NOx emissions from fertilisers and the soil only. Other sources such as tractor exhaust gases are included in the respective inventories.

$\left.\mathrm{NO}_{\mathrm{x}}=0.21 \times \mathrm{N}_{2} \mathrm{O}\right)$

3.2.4.3. $\mathrm{NH}_{3}$ emission to air. Emission of ammonia $\left(\mathrm{NH}_{3}-\mathrm{N}\right.$ is calculated as percentage (\%) loss of $\mathrm{N}$ content from inorganic mineral fertilizer
(Nemecek et al., 2014; Schmidt, 2007). The amount of $\mathrm{NH}_{3}$ emitted to air depends on the kind of nitrogen fertilizer application. In this study, calcium ammonium nitrate was adopted based on reference (Castanheira et al., 2015). The emission was calculated as shown in equation (2)

$\mathrm{NH}_{3}=2 \% \mathrm{~N}$ Fertilizer

3.2.4.4. Phosphorus emissions to water. The phosphorus emissions to water were estimated based on reference (Nemecek et al., 2014) using equation (3)

$\mathrm{P}\left[\frac{\mathrm{kg}}{\mathrm{ha}}\right]$ to surface water $=0.175 \times(1+0.0025 \mathrm{P} 2 \mathrm{O5})$

\subsubsection{Oil extraction and refining produce SVO}

Oil extraction is usually done by cooking and grinding of the seeds, to facilitate the oil extraction process. During mechanical pressing of the seeds, a protein-rich cake is also produced. This cake is usually used in animal feed (Castanheira et al., 2015). The press cake has, however, high oil content and a further (chemical) extraction step is conducted to extract the remaining oil, in order to increase the overall vegetable oil yield (Milazzo et al., 2013). Chemical extraction uses a petroleum-derived solvent (hexane) and when used, the oil goes through a distillation process to recover the hexane, which is recycled back to the oil extraction process (Milazzo et al., 2013). The final step in the production of SVO is oil refining, which includes degumming, neutralisation and drying. Gums are precipitated by the addition of hot water and phosphoric (or equivalent) acid and separated out by centrifugal separation (Esteban et al., 2011). Free fatty acids in the oil are converted to soap using an alkali solution of sodium hydroxide, which is subsequently removed by continuous centrifugation and treated as a residue. Finally, the oil is vacuum dried to remove any traces of water (Esteban et al., 2011). The refinery output for extraction and refining of SVO in the United Kingdom is based on the EU average (Milazzo et al., 2013; Malca et al., 2014; Castanheira et al., 2015). It is assumed that oil extraction mills consume electricity from the national grid. The Inventory data for extraction of crude soy based SVO if produced in Argentina is adopted from the literature (Garraín et al., 2014).

\subsubsection{Transesterification of SVO to produce biodiesel}

In the transesterification reaction, the triglyceride molecules of the oil are reacted with methanol in the presence of an alkaline catalyst (usually sodium methylate, potassium hydroxide or sodium hydroxide) to improve the reaction rate and yield, producing a mixture of biodiesel and glycerine (Esteban et al., 2011). After settling, glycerine is left at the bottom and biodiesel is left on top. Finally, biodiesel is recovered, washed and filtered (Malca et al., 2014). The refinery output for esterification is adopted from literature (Castanheira et al., 2015).

\subsubsection{Oil pumping and bunkering}

This study assumed that once the oil products leave the refinery they are pumped to location at a port and loaded onto bunker ships for subsequent transportation. The energy intensity of pumping oil products is assumed to be $0.2 \mathrm{Mj} /$ ton-km (Weber and Matthews, 2008). It is assumed that electricity is provided from the grid and that oil is pumped $20 \mathrm{~km}$ it is assumed that the refinery (extracting, refining and transesterification) is located at the port and vessels are refuelled through a bunker ship. The bunkership details were taken from literature (Bengtsson et al., 2011) and it was assumed that the vessel had a capacity of $6370 \mathrm{dwt}$ with an average engine loading and operational speed of $85 \%$ and 8 knots respectively (Bengtsson et al., 2011). The bunker ship vessel haul length of $10 \mathrm{~km}$ was assumed and applied to estimate emissions. It was assumed that the vessel was fuelled by distillate oil with a Sulphur content of $0.1 \% \mathrm{w} / \mathrm{w}$. The biofuel was assumed to be transported to the port by pipeline and subsequently 


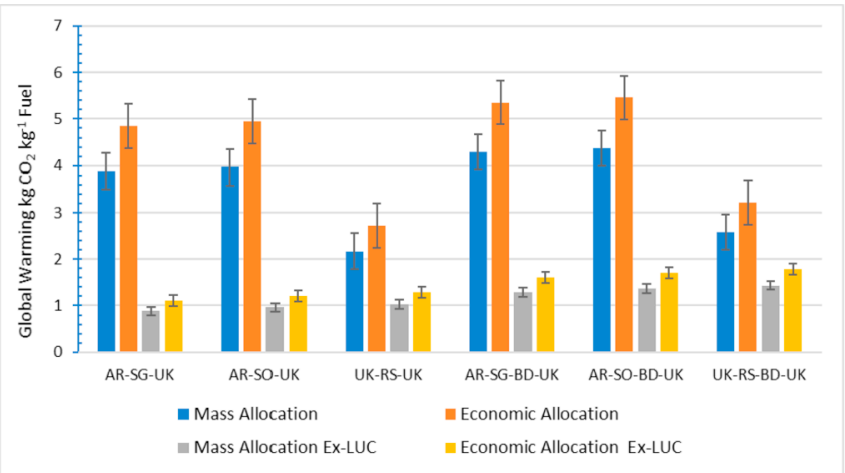

Fig. 3. Global warming impact of soy and rape based SVO and biodiesel (mass and economic allocation).

transported by a tanker a short distance from bunkering facility within a European port to a ship, where it was combusted in a slow-speed diesel engine.

\section{Results and discussion}

This section presents an analysis of ALCA of SVO and biodiesel production addressing alternative upstream pathways. The pathways are SVO and biodiesel produced in the UK using European rapeseed and also, SVO and biodiesel produced in the UK using soybean grain and soybean oil imported from Argentina. The types of the impacts that were examined includes $\mathrm{CO}_{2}$ equivalent $\left(\mathrm{CO}_{2}, \mathrm{CH}_{4}\right.$ and $\left.\mathrm{N}_{2} \mathrm{O}\right)$ to assess Global Warming Potential; SOx and NOx to assess Acidification and Eutrophication Potential and PM emissions. The contribution of each life cycle process to the environmental impacts was also analysed.

\subsection{Global warming potential (GWP)}

The GWP impacts of SVO and biodiesel production systems is shown in Figs. 3 and 4. For SVO production systems the GHG intensity varies from 0.88 to $4.95 \mathrm{kgCO}_{2}$ eq $\mathrm{kg}^{-1}$ while biodiesel varies from 1.29 to 5.5 $\mathrm{kgCO}_{2} \mathrm{eq} \mathrm{kg}^{-1}$ depending on the allocation method and feedstock location. A sensitivity study of different allocation methods for the treatment of co-products using the economic and mass allocation factors was performed, mass allocation results has lower environmental impacts for all categories compared to the economic allocation (Fig. 3). The GHG intensity of biofuel calculated with price allocation depends on the oil and meal prices variability. Similar results were reported in the literature (Malca et al., 2014). However, it should be noted that the

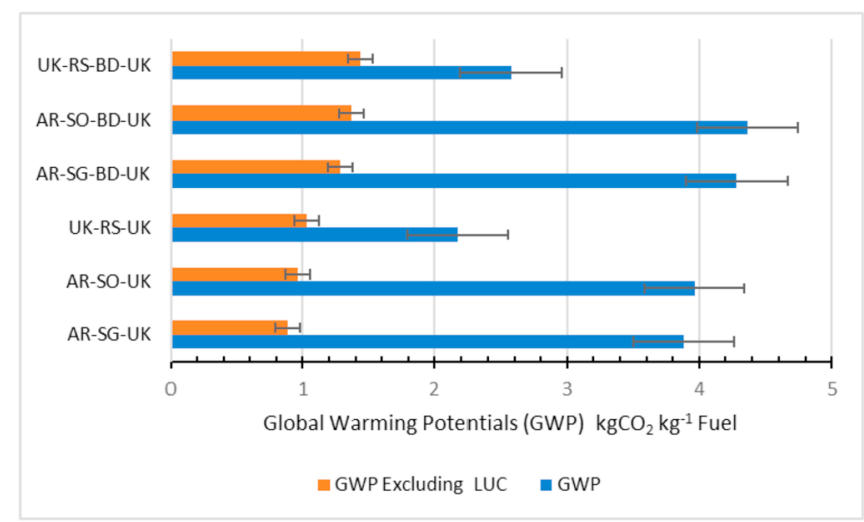

Fig. 4. a: Comparing emission of the fuel pathways in terms of global warming impact. b: Main Contributions to the global warming Potentials of soy and rapeseed based SVO and Biodiesel.

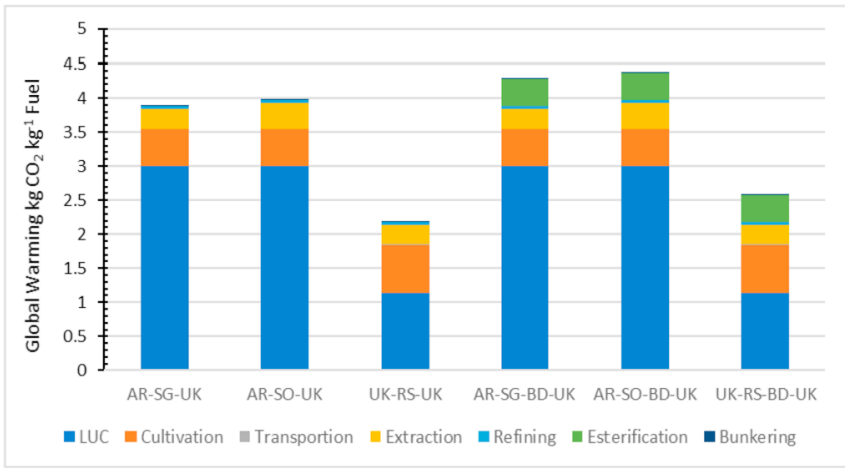

Fig. 4. (continued)

influence of the allocation approach depends on the relative contribution of the life cycle stages for each impact category and for this reason the results are not only a reflection of the differences in the allocation factors adopted. The GHG intensity of biofuel depends on the allocation approach applied. The results calculated with price allocation is about $35-40 \%$ higher than for mass allocation.

The cultivation and geographical variability of feedstock also has a strong influence on environmental impacts and also, on the choice of the pathway with the lowest impacts due to the differences in the yield and LUC in different countries. The most representative climates assumed for rapeseed cultivation in the UK are as follows: cold temperate, moist climate and high activity clay soil (Castanheira et al., 2015; Malca et al., 2014). In Argentina, about $76 \%$ of soybean (2009/2010) was produced in the provinces of Buenos Aires, Córdoba and Santa Fé in the Las Pampas region, characterized by a warm temperate dry climate and high activity clay soils (Castanheira et al., 2015). To quantify extreme scenarios in terms of soil carbon content in the reference land use, high and low carbon inputs have been considered, whereas in the actual land use the option for medium inputs to rapeseed and soybean cultivation were selected. The results show significant greenhouse gas (GHG) emissions resulted from LUC due to the expansion and cultivation of soybean grain in Argentina. The GHG intensity for Soy based SVO was $4.0 \mathrm{kgCO}_{2}$ eq kg ${ }^{-1}$ while rape based SVO was estimated as $2.17 \mathrm{kgCO}_{2} \mathrm{eq} \mathrm{kg}^{-1}$. For biodiesel production systems, soy based biodiesel was $4.4 \mathrm{kgCO}_{2}$ eq $\mathrm{kg}^{-1}$ while rape based biodiesel was 2.57 $\mathrm{kgCO}_{2}$ eq $\mathrm{kg}^{-1}$. The LUC GHG emissions contributed to more than $70 \%$ of the total GHG emission of soybean based SVO and biodiesel production. When LUC was not considered the overall GHG intensity reduced to $0.88 \mathrm{kgCO}_{2}$ eq $\mathrm{kg}^{-1}$ and $1.28 \mathrm{kgCO}_{2}$ eq $\mathrm{kg}^{-1}$ for soy based SVO and biodiesel production systems respectively. Panichelli et al., 2009 also reported similar result of high contribution of LUC to the overall environmental impacts of soybean production systems. Land use change scenarios and carbon stock changes were established on the basis of a combination of alternative previous land uses, different cultivation systems (tillage, reduced tillage and no-tillage), climate (tropical moist, and warm temperate, moist and dry) and soil characteristics (low and high activity clay soils). To address this issue, this article assesses the most representative cultivation system for rapeseed-based biodiesel marketed in Europe, namely rapeseed cultivated in existing cropland, and evaluates the implications of changing soil management activities in the global warming impact of biofuel while Argentine soybean is assumed to be mainly associated with an expansion in cultivation. Table 4 shows the contribution of LUC, cultivation and geographical variability on the LCA results.

Nitrous oxide $\left(\mathrm{N}_{2} \mathrm{O}\right)$ emissions from soils due to the application of nitrogen fertilizers and transportation are another main contributor to the GWP of cultivation. A comparative LCA of different stages of the biofuel production systems is shown in Table 4. The result shows that emissions of cultivation far outweigh the environmental impacts of the other life-cycle stages. Similar results was reported in the literature 
Table 4

The contribution of each life cycle process to the environmental impact.

\begin{tabular}{|c|c|c|c|c|c|c|c|}
\hline Impact category per life cycle stage & $\begin{array}{l}\text { Biofuel Production } \\
\text { Pathways }\end{array}$ & Cultivation and LUC & Transport & Extraction & Refining & Esterification & $\begin{array}{l}\text { Pumping and } \\
\text { Bunkering }\end{array}$ \\
\hline Global Warming Potential $\left[\mathrm{kgCO}_{2 \mathrm{eq}} \mathrm{kg}^{-1}\right.$ & AR-SG-UK & 3.540 & 0.0100 & 0.2940 & 0.020 & - & 0.0004 \\
\hline \multirow{5}{*}{ Fuel] } & AR-SO-UK & 3.540 & 0.0098 & 0.3750 & 0.020 & - & 0.0004 \\
\hline & UK-RS-UK & 1.840 & 0.0092 & 0.2840 & 0.020 & - & 0.0004 \\
\hline & AR-SG-BD-UK & 3.540 & 0.0100 & 0.2940 & 0.020 & 0.401 & 0.0004 \\
\hline & AR-SO-BD-UK & 3.540 & 0.0098 & 0.3750 & 0.020 & 0.401 & 0.0004 \\
\hline & UK-RS-BD-UK & 1.840 & 0.0092 & 0.2840 & 0.020 & 0.401 & 0.0004 \\
\hline \multirow[t]{6}{*}{ Acidification $\left[\mathrm{kgSO}_{2} \mathrm{eq} \mathrm{kg}^{-}{ }^{1} \mathrm{Fuel}\right]$} & AR-SG-UK & 0.0045 & 0.0012 & 0.0002 & 0.0001 & - & 0.0001 \\
\hline & AR-SO-UK & 0.0049 & 0.0010 & 0.0002 & 0.0001 & - & 0.0001 \\
\hline & UK-RS-UK & 0.0067 & 0.0008 & 0.0002 & 0.0001 & - & 0.0001 \\
\hline & AR-SG-BD-UK & 0.0045 & 0.0012 & 0.0002 & 0.0001 & 0.0004 & 0.0001 \\
\hline & AR-SO-BD-UK & 0.0049 & 0.0008 & 0.0002 & 0.0001 & 0.0004 & 0.0001 \\
\hline & UK-RS-BD-UK & 0.0067 & 0.0010 & 0.0002 & 0.0001 & 0.0004 & 0.0001 \\
\hline \multirow{6}{*}{ Eutrophication $\left[\mathrm{kg} \mathrm{P}_{\mathrm{eq}} \mathrm{kg}^{-1}\right.$ Fuel] } & AR-SG-UK & 0.00117 & 0.000371 & 0.00010 & 0.00002 & - & 0.000025 \\
\hline & AR-SO-UK & 0.00117 & 0.000371 & 0.00015 & 0.00002 & - & 0.000025 \\
\hline & UK-RS-UK & 0.00113 & 0.000316 & 0.00010 & 0.00002 & - & 0.000025 \\
\hline & AR-SG-BD-UK & 0.00121 & 0.000396 & 0.00010 & 0.00002 & 0.0003 & 0.000025 \\
\hline & AR-SO-BD-UK & 0.00121 & 0.000394 & 0.00015 & 0.00002 & 0.0003 & 0.000025 \\
\hline & UK-RS-BD-UK & 0.00114 & 0.000316 & 0.00011 & 0.00002 & 0.0003 & 0.000025 \\
\hline \multirow[t]{6}{*}{ PM $\left[\mathrm{kg} \mathrm{PM} \mathrm{kg}^{-1}\right.$ Fuel $]$} & AR-SG-UK & 0.000235 & 0.000084 & 0.000002 & 0.00000 & - & 0.000002 \\
\hline & AR-SO-UK & 0.000245 & 0.000084 & 0.000002 & 0.00000 & - & 0.000002 \\
\hline & UK-RS-UK & 0.000268 & 0.000092 & 0.000002 & 0.0000 & - & 0.000002 \\
\hline & AR-SG-BD-UK & 0.000270 & 0.000097 & 0.000002 & 0.00001 & 0.0004 & 0.000002 \\
\hline & AR-SO-BD-UK & 0.000273 & 0.000097 & 0.000002 & 0.00001 & 0.0005 & 0.000002 \\
\hline & UK-RS-BD-UK & 0.000286 & 0.000099 & 0.000003 & 0.00001 & 0.0005 & 0.000002 \\
\hline
\end{tabular}

(Malça and Freire, 2010). The use of fertilizers, associated soil and land use change emissions are the main contributors.

$\mathrm{N}_{2} \mathrm{O}$ is a potent greenhouse gas, with an impact 298 times stronger than the reference carbon dioxide for a 100-year time horizon (Milazzo et al., 2013). This explains why the cultivation stage has a higher share in global warming results. The great variation in GHG emissions for the rapeseed and soybean cultivation systems and can be explained by the variation in fertilizer, lime and diesel inputs. When LUC is not examined, rape based SVO and biodiesel systems had higher $\mathrm{N}_{2} \mathrm{O}$ and $\mathrm{CH}_{4}$ emissions compared to soybean based SVO and biodiesel. The reason was the to higher application rate of nitrogen fertilizer for rapeseed during cultivation compared to soybean. For example the nitrogen fertilizer requirement for rapeseed cultivation in the UK is $161 \mathrm{kgha}^{1}$ while for soybean cultivation in Argentina is $5.47 \mathrm{~kg} \mathrm{ha}^{-1}$. This is due to biological $\mathrm{N}$ fixation which can provide the majority of the required $\mathrm{N}$ supply for soybean, unless there are soil restrictions for a normal nodule activity (e.g. moisture stress, soil temperature stress, soil $\mathrm{pH}$ ). Therefore, $\mathrm{N}$ fertilization would only be profitable where $\mathrm{N}_{2}$ fixation was not able to meet the total $\mathrm{N}$ demand of high yielding soybeans.

A sensitivity analysis to field $\mathrm{N}_{2} \mathrm{O}$ emissions was implemented, since there is significant uncertainty regarding the emission factors and partitioning fractions (volatilization and leaching factors) adopted in calculations (IPCC et al., 2013). Default, maximum and minimum values from the IPCC study for emission factors and partitioning fractions were adopted to assess the influence on field $\mathrm{N}_{2} \mathrm{O}$ emission calculations. Field $\mathrm{N}_{2} \mathrm{O}$ emissions (default) are the most important contributions to the GHG emissions from cultivation (between 30 and 65\%) except under the tillage system, where the emissions from the use of machinery contribute about $30 \%$. Regarding the sensitivity analysis of the field $\mathrm{N}_{2} \mathrm{O}$ emissions, the result shows that the uncertainty in $\mathrm{N}_{2} \mathrm{O}$ emission calculations is high and dominates GHG cultivation emissions. However, when minimum parameters and emission factors are adopted, the emissions from cultivation are reduced by $10-35 \%$. If the maximum parameters and emission factors are adopted, cultivation emissions increase by $80-160 \%$ and the field $\mathrm{N}_{2} \mathrm{O}$ emissions dominate $(60-80 \%)$ the results for all cultivation systems. These results show that GHG emissions from cultivation are very sensitive to the parameters and emission factors adopted for field $\mathrm{N}_{2} \mathrm{O}$ emissions calculations. Diesel for agricultural machinery represents $15-20 \%$ of the total GHG emissions, with a higher contribution under tillage systems than the corresponding no- or reduced tillage systems. This is another reason for the variations in GHG emissions in the cultivation systems.

\subsubsection{Comparing fuel production pathways in terms of GWP}

Comparing the pathways for the SVO production systems as shown in Figs. 1 and 2, the lowest GHG intensity was calculated for pathway UK-RS-UK (when rapeseed is cultivated in the UK and processed in the UK) while the highest GHG intensity was calculated for fuel pathway AR-SG-UK and AR-SO-UK (when soybean is cultivated in Argentina and imported to UK as soybean grain and/or soybean oil) as shown in Fig. 4a and b. Similarly, an analysis of the biodiesel production pathways shows that the lowest GHG intensity was calculated for UK-RS-BDUK (rapeseed in cultivated in UK) while the highest GHG emission was calculated for AR-SG-BD-UK and AR-SO-BD-UK (when soybean in cultivated in Argentina and imported to UK for process as soybean grain/ or soybean oil) (Fig. 4a). The overall GHG emission results greatly depend on the $\mathrm{CO}_{2}$ emissions from LUC, which contributes more than $70 \%$ for the GHG intensity of the alternative pathways for soybean production systems, irrespective of the allocation approach adopted (Fig. 4b). These results shows that the choice of importing soybean grain or oil from Argentina (as compared to rapeseed cultivated in the UK) will be based on GHG intensity of which LUC is the major contributor.

\subsection{Acidification potential}

The acidification impact accounts for the wide range of environmental impacts caused by the release of acidifying substances. The results show that rapeseed based SVO and biodiesel production systems have greater acidification impact when compared to soybean based production systems. The reason is due to higher rate of fertilization application required for rapeseed cultivated in UK when compared to soybean cultivated in Argentina. The cultivation stage dominates the acidification impact mainly due to ammonia and nitrogen oxides released during rapeseed growth. However, lower fuel quality in ship transportation, up to a maximum sulphur content of $1.0 \%$ (heavy fuel 


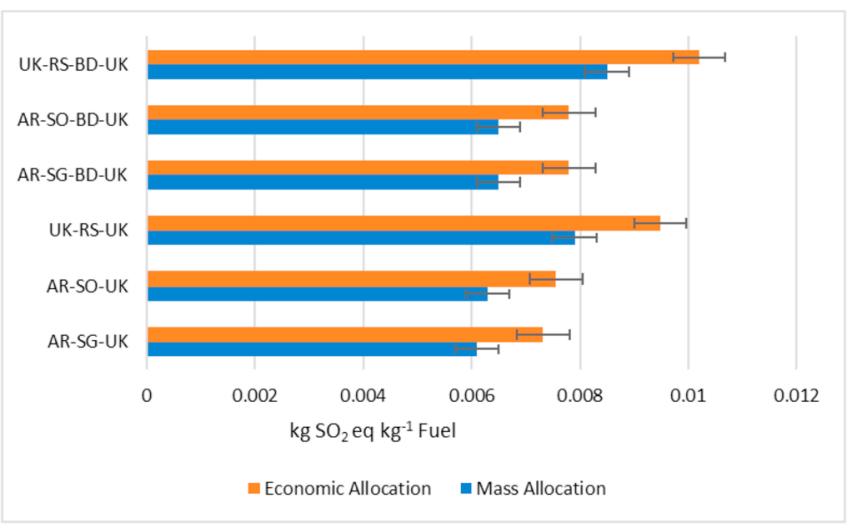

Fig. 5. a: Comparing emissions of the fuel pathways in terms of acidification impact. b: Main Contributions to the acidification potentials of soy and rapeseed based SVO and Biodiesel.

oil), may have significant impact to acidification particularly for the soy based SVO and biodiesel systems if soybean grain and oil needs to be imported. Soy based SVO and biodiesel have lower acidification impact when to rapeseed based SVO and biodiesel regardless of the allocation approach adopted (Fig. 5).

Comparing fuel production pathways in terms of acidification potential, the results in Fig. 5 show that the fuel Pathways AR-SG-UK and AR-SO-UK have the lowest acidification impact results when mass allocation were adopted (8-10\% lower) for SVO production systems. Furthermore, for biodiesel production systems AR-SO-BD-UK and ARSG-BD-UK have lower acidification potentials when compared to the rapeseed based biodiesel production system (UK-RS-BD-UK) [Fig. 5]. However, transportation emissions (mainly due to soybean grain importation) may contribute to higher acidification impact depending on the quality of fuel used in the shipping transportation. The contribution of each life cycle processes to the acidification impact of SVO and biodiesel production systems was as follows: $53-69 \%$ due to cultivation, transport, $20-41 \%, 3-10 \%$ to transesterification and less than $4 \%$ to oil extraction and refining. $\mathrm{NOx}$ and $\mathrm{SO}_{2}$ emissions related with fuel combustion for transportation, agricultural operations and for electricity and heat production at oil extraction and biodiesel plants contributed most to acidification impact. An analysis per life-cycle stage reveals cultivation and transportation as the major sources of acidification impact (Fig. 5b).

\subsection{Eutrophication potential}

Eutrophication covers all potential impacts of excessively high environmental levels of macronutrients, namely nitrogen and phosphorus. The cultivation stage dominates the impacts when compared to other stages of fuel production (Fig. 6). This is due the subsequent excessive supply of nutrients to the environment from nitrate and phosphate

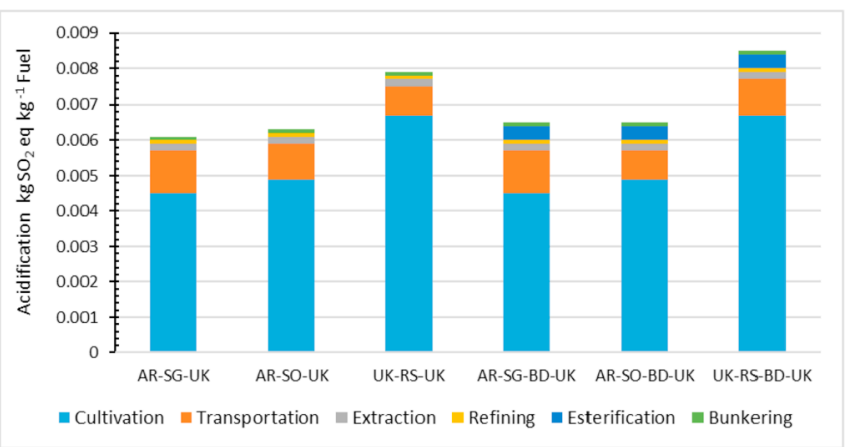

Fig. 5. (continued)

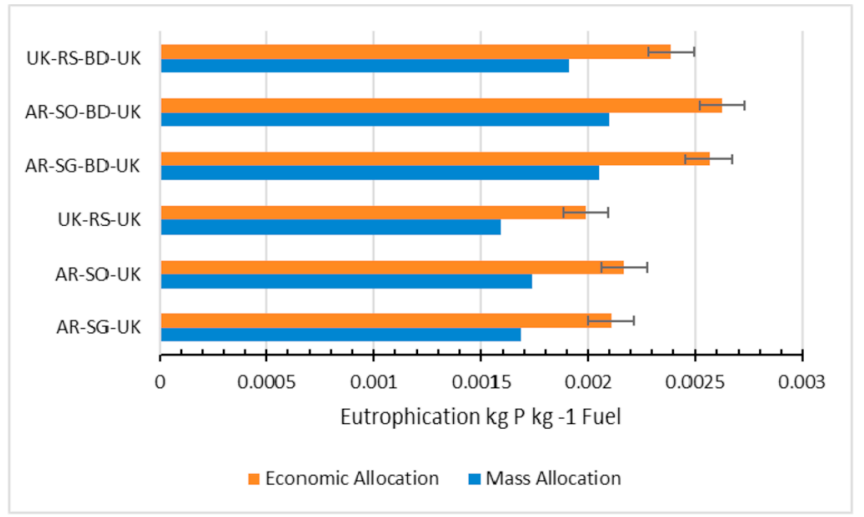

Fig. 6. Comparing emission of the fuel pathways in terms of eutrophication impact. b: Main Contributions to the Eutrophication potentials of soy and rapeseed based SVO and Biodiesel.

fertilizer runoff. Nitrate and ammonia are the most important substances. The eutrophication impacts of SVO and biodiesel production systems as calculated for the alternative pathways is presented in Fig. 6. The freshwater eutrophication impact of SVO and biodiesel production systems was mainly caused by phosphorus emissions. UK-RS-UK has the lowest eutrophication impact when compared to soybean based SVO and the biodiesel production system (Fig. 6). Although there was a lower application of P-fertilizer in soybean cultivated in Argentina, the reason may be due to the lower uptake of nitrogen by the crop (lowest yield) and, consequently, more nitrates being leached.

\subsection{Particulate matter (PM)}

A significant portion of PM is generated from agricultural operations, industrial processes, combustion of fossil fuels, and transportation (Table 4). Secondary PM sources emit air contaminants into the atmosphere that form or help form PM. Hence, these pollutants are considered precursors to PM formation. These secondary pollutants include SOx, NOx, VOCs, and ammonia. Control measures that reduce PM precursor emissions tend to have a beneficial impact on ambient PM levels. The PM emission of soy based SVO is $0.00032 \mathrm{~kg}$ PMeq kg-1 while rapeseed based SVO is 0.00036 PMeq kg- 1 . Similar results were calculated for biodiesel production systems. Sensitivity analysis of different allocation methods for the treatment of co-products using the economic and mass allocation factors shows that mass allocation results in lower PM emission impact when compared to economic allocation. Comparing the fuel production pathways shows that rape based SVO and biodiesel has slightly higher PM emission when compared to soy based SVO. This may be due to higher emission impact at cultivation stage due to the use of tractors and other related soil emissions and fertilizer application (Table 4).

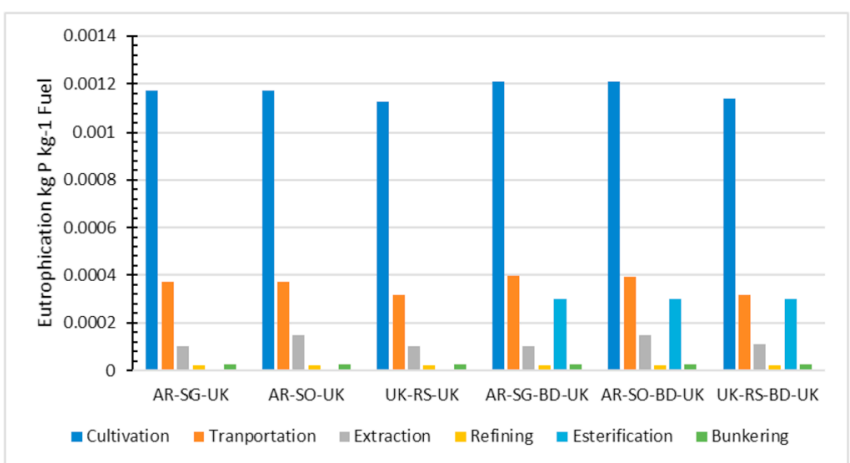

Fig. 6. (continued) 


\section{Conclusions}

This paper evaluates the LCA of upstream pathways towards environmentally effective biofuels for shipping, taking into account alternative geographical locations and cultivation system. Environmental impacts including global warming potentials, acidification, eutrophication, and PM were calculated using different allocation methods. The lowest environmental impacts were calculated for mass allocation and the highest for economic allocation. Comparing the LCA of fuel production pathways shows that the lowest GHG intensity was calculated for pathway UK-RS-UK and UK-RS-BD-UK (when rapeseed is cultivated in the UK and processed in the UK to produce SVO and biodiesel, respectively) while the highest was calculated for fuel pathway AR-SO-UK, AR-SO-UK, and AR- SG-BD-UK (when soybean in cultivated in Argentina and imported to UK). The cultivation location has a strong influence on environmental impacts and on the choice of the pathway with the lowest impacts due to the differences in yield and LUC. When LUC is not considered, the soybean based biofuel system has lowest GHG impact with more than 70\% GHG emission reduction. Results show that the environmental impacts of cultivation of oil seed far outweigh the impacts of the other life-cycle stages. Concerning soil management practices, it was observed that all the tillage systems have higher GHG emissions than the corresponding reduced tillage and notillage systems. A sensitivity analysis for $\mathrm{N}_{2} \mathrm{O}$ emission calculations was also presented, showing a high level of uncertainty in the calculation of $\mathrm{N}_{2} \mathrm{O}$ emissions. This study demonstrates that LCA is a suitable methodology to analyse the environmental performance of biofuels and compare alternative production systems aiming at identifying critical aspects, improvement opportunities, and select the biomass feedstock and processes with lower impacts.

\section{Acknowledgement}

The financial support of the Engineering and Physical Sciences Research Council (EPSRC) Shipping in Changing Climates project (EP/ K039253/1) is gratefully acknowledged.

\section{References}

Anderson, K., Bows, A., 2011. Beyond 'dangerous' climate change: emission scenarios for a new world. Philos. Trans. R. Soc. A Math. Phys. Eng. Sci. 369, 20-44.

Bengtsson, S., Fridell, E., Anderson, K., 2012. Environmental assessment of two pathways towards the use of biofuels in shipping. Energy Policy 44, 451-463.

Bengtsson, S., Andersson, K., Fridell, E., 2011. A comparative life cycle assessment of marine fuels liquefied natural gas and three other fossil fuels. Proc. Inst. Mech. Eng. Part M J. Eng. Marit. Environ. 225, 97-110.

Brynolf, S., 2014. Environmental Assessment of Present and Future Marine Fuels. Thesis for Degree of Doctor of Philosophy. Chalmers University of Technology, Gothenburg, Sweden (Department of Shipping and Marine Technology).

Brynolf, S., Fridell, E., Andersson, K., 2014. Environmental assessment of marine fuels: liquefied natural gas, liquefied biogas, methanol and bio-methanol. J. Clean. Prod. $74,86-95$.

Castanheira, E.G., Grisoli, R., Coelho, S., Freire, F., 2015. Life-cycle assessment of soybean-based biodiesel in Europe: comparing grain, oil and biodiesel import from Brazil. J. Clean. Prod. 102, 188-201.

Corbett, J.J., Winebrake, J.J., 2008. Emissions trade-offs among alternative marine fuels: total fuel cycle analysis of residual oil, marine gas oil, and marine diesel oil. J. Air Waste Manag. Assoc. 58, 538-542.

Dalgaard, R., Schmidt, J., Halberg, N., Christensen, P., Thrane, M., Pengue, W.A., 2008. LCA of soybean meal. Int. J. Life Cycle Assess. 3, 240-254.

DEFRA, 2013. The British Survey of Fertilizer Practice: Fertilizer Use on Farm Crop for Crops. Available online:www.gov.uk/government/uploads/system/uploads/ attachment_data/file/301474/fertiliseruse-report2013-08apr14.pdf , Accessed date: 22 June 2018.

Esteban, B., Baquero, G., Puig, R., Riba, J., Rius, A., 2011. Is it environmentally advantageous to use vegetable oil directly as biofuel instead of converting it to biodiesel? Biomass Bioenergy 35 1317-132.

FAO, 2018. Available online: http://www.fao.org/forestry/17111/en/ Last accessed June, 2018.

Fazio, S., Monti, A., 2011. Life cycle assessment of different bioenergy production systems including perennial and annual crops. Biomass Bioenergy 35, 4868-4878.

Florentinus, A., Hamelinck, C., Winkel, R., Cuijpers, M., 2012. Potential of Biofuels for Shipping. ECOFYS Netherlands BV, Utrecht.
Garraín, D., Herrera, I., Lechón, Y., Lago, C., 2014. Well-to-Tank environmental analysis of a renewable diesel fuel from vegetable oil through co-processing in a hydrotreatment unit. Biomass Bioenergy 63, 239-249.

Gilbert, P., Walsh, C., Traut, M., Kesieme, U., Pazouki, K., Murphy, A., 2018. Assessment of full life-cycle air emissions of alternative shipping fuels. J. Clean. Prod. 172, 855-866.

Hennecke, A., Faist, M., Reinhardt, J., Junquera, V., Neeft, J., Fehrenbach, H., 2013. Biofuel greenhouse gas calculations under the European renewable energy. Appl. Energy 102, 55-62.

Hilbert, J.A., 2010. Biodiesel, greenhouse gas calculation and some cases in soy producing countries: Argentina soybean biodiesel case study. Available online. http://inta.gob. ar/ last accessed June, 2018.

Hilbert, J.A., Donato, L.B., Muzio, J., Huerga, I., 2009. Comparative analysis of energetic consumption and greenhouse gas emissions from the production of biodiesel from soy under conventional and no till farming systems. Boletín 6 Doc N IIR-BC-INF-06-09 INTA, Argentina.

IPCC, 2006. Guidelines for National Greenhouse Gas Inventories. Available online:. https://www.ipcc-nggip.iges.or.jp/public/2006gl/vol4.html [last accessed January, 2019].

IPCC, 2013. Climate change 2013: the physical science basis. In: Stocker, T.F., Qin, D., Plattner, G.-K., Tignor, M., Allen, S.K., Boschung, J., Nauels, A., Xia, Y., Bex, V., Midgley, P.M. (Eds.), Contribution of Working Group I to the Fifth Assessment Report of the Intergovernmental Panel on Climate Change. Cambridge University Press, Cambridge, United Kingdom and New York, NY, USA.

Jungbluth, N., Chudacoff, M., Dauriat, A., Dinkel, F., Doka, G., Faist Emmenegger, M., Guasounous, E., Klgun, N., Schlesis, K., Spielmann, M., Stettler, C., Sutter, J., 2007. Life Cycle Inventory of Bioenergy. Centre for Life Cycle inventories, Dubendorf. CH: Swiss.

Koponen, k., Soimakallio, S., Tsupari, E., Thun, R., Antikainen, R., 2013. GHG emission performance of various liquid transportation biofuels in Finland in accordance with the EU sustainability criteria. Appl. Energy 102, 440-448.

Lechón, Y., Cabal, H., Rúa, C., Caldés, N., Santamaría, M., Sáez, R., 2009. Energy and greenhouse gas emission savings of biofuels in Spain's transport fuel. The adoption of the EU policy on biofuels. Biomass Bioenergy 33, 920-932.

Malca, J., Coelho, A., Ferire, F., 2014. Environmental life-cycle assessment of rapeseedbased biodiesel: alternative cultivation systems and locations. Appl. Energy 114, 837-844.

Malça, J., Freire, F., 2010. Uncertainty analysis in biofuel systems: an application to the life cycle of rapeseed oil. J. Ind. Ecol. 14, 322-334.

Malça, J., Freire, F., 2011. Life-cycle studies of biodiesel in Europe: a review addressing the variability of results and modelling issues. Renew. Sustain. Energy Rev. 15, 338-351.

Milazzo, M.F., Spina, F., Cavallaro, S., Bart, J.C.M., 2013. Sustainable soy biodiesel. Renew. Sustain. Energy Rev. 27, 806-852.

Nemecek, T., Weilera, K., Plassmann, K., Schnetzera, J., Gaillard, G., Jefferies, D., Garcia-Suarez, T., King, H., Mila I Canals, L., 2012. Estimation of the variability in global warming potential of worldwide crop production using a modular extrapolation approach. J. Clean. Prod. 31, 106-117.

Nemecek, T., Bengoa, X., Lansche, J., Mouron, P., Rossi, V., Humbert, S., 2014. World Food LCA Database Methodological Guidelines for the Life Cycle Inventory of Agricultural Products. http://www.quantisintl.com/files/2714/0626/8848/WFLDB MethodologicalGuidelines_20140723_v2.0.pdf Available online:[last accessed, June 2018].

Panichelli, L., Dauriat, A., Gnansounou, E., 2009. Life cycle assessment of soybean-based biodiesel in Argentina for export. Int. J. Life Cycle Assess. 2, 144-159.

Petzold, A., Lauer, P., Fritsche, U., Hasselbach, J., Lichtenstern, M., Schlager, H., Fleischer, F., 2011. Operation of marine diesel engines on biogenic fuels: modification of emissions and resulting climate effects. Environ. Sci. Technol. 45, 10394-10400.

Proskilly, A.P., Nanda, S.K., Wang, Y.D., Chirkowski, J., 2008. The performance and the gaseous emissions of two small marine craft diesel engines fuelled with biodiesel. Appl. Therm. Eng. 28, 872-880.

Rocha, M.H., Capaz, R.S., Silva Lora, E.E., Nogveira, L.A.H., Leme Vicente, M.M., Reno, M.L., Olmo, O.A., 2014. Life cycle assessment (LCA) for biofuels in Brazilian conditions: a meta-analysis. Renew. Sustain. Energy Rev. 37, 435-459.

Rehmatulla, N., Smith, T., 2015. Barriers to energy efficiency in shipping: a triangulated approach to investigate the principal agent problem. Energy Policy 84, 44-57.

Reijnders, L., Huijbregts, M., 2008. Biogenic greenhouse gas emissions linked to the life cycles of biodiesel derived from European rapeseed and Brazilian soy-beans. J. Clean. Prod. 16, 1943-1948.

Schmidt, J., 2007. Life Cycle Assessment of Rapeseed Oil and Palm Oil: Ph.D. Thesis, Part 3: Life Cycle Inventory of Rapeseed Oil and Palm Oil. Department of Planning and Development, Aalborg University, Aalborg.

Taljegard, M., Selma Brynolf, S., Grahn, M., Andersson, K., Johnson, H., 2014. Cost effective choices of marine fuels in a carbon-constrained world: results from a global energy model. Environ. Sci. Technol. 48, 12986-12993.

Thamsiriroj, T., Murphy, J., 2011. A critical review of the applicability of biodiesel and grass biomethane as biofuels to satisfy both biofuel targets and sustainability criteria. Appl. Energy 88, 1008-1019.

Tonini, D., Astrup, T., 2012. LCA of biomass-based energy systems: a case study for Denmark. Appl. Energy 99, 234-246.

Weber, C.L., Matthews, H.S., 2008. Food-miles and the relative climate impacts of food choices in the United States. Environ. Sci. Technol. 42, 3508-3513.

Winebrake, J.J., Corbett, J.J., Meyer, P.E., 2007. Energy use and emissions from marine vessels: a total fuel life cycle approach. J. Air Waste Manag. Assoc. 57, 102-110. 